\title{
Editorial: Lessons on Building More Sustainable Rural Societies: Youth and Mobility
}

\author{
Slaven Gasparovic ${ }^{1, *}$ and Òscar Prieto-Flores ${ }^{2, *}$ D \\ 1 Department of Geography, Faculty of Science, University of Zagreb, 10000 Zagreb, Croatia \\ 2 School of Education \& Psychology, University of Girona, 17071 Girona, Spain \\ * Correspondence: slaveng@geog.pmf.hr (S.G.); oscar.prieto@udg.edu (Ò.P.-F.)
}

check for updates

Citation: Gasparovic, S.; Prieto-Flores, Ò. Editorial: Lessons on Building More Sustainable Rural Societies: Youth and Mobility. Sustainability 2021, 13, 10370. https: / / doi.org/10.3390/su131810370

Received: 3 September 2021

Accepted: 13 September 2021

Published: 17 September 2021

Publisher's Note: MDPI stays neutral with regard to jurisdictional claims in published maps and institutional affiliations.

Copyright: (c) 2021 by the authors. Licensee MDPI, Basel, Switzerland. This article is an open access article distributed under the terms and conditions of the Creative Commons Attribution (CC BY) license (https:/ / creativecommons.org/licenses/by/ $4.0 /)$.
Mobility is a fundamental and important characteristic of human activity: it fulfils the basic need of going from one location to the other in order to partake in employment, kinship, and education. As such, mobility enables social, cultural, political, and economic activities to take place with relative ease. Mobility is the recurring factor where transportation exerts its most significant impact upon society in a multiplicity of ways [1]. However, mobility in rural areas and its associated impact upon social inclusion and rural development is a phenomenon that has been poorly studied until today. One example of this is the scarcity of evidence examining how international migrants or asylum seekers are included within rural areas of the EU [2]. This concept can be taken in plural since it can be seen in some of the articles found in this Special Issue, providing analytical insight by delving into the different typologies of mobilities but also of (im)mobilities affecting youth in rural areas. This tension between the freedom and lack of freedom to move can generate new inequalities or even increase existing ones [3]. Hence, it is necessary to explore the mobility dichotomy: namely, (im)mobility and whether rural youth voluntarily or involuntarily leave or stay in their hometowns but also how the mobility of some is inevitably linked to the immobility of others [4]. For some social groups, constrictions are more evident, but this is also the case for some geographical areas, given that sustainable development is unequally distributed. To that end, the study of the different categories of mobility and immobility (and their interconnections) becomes central for analysing social change and thereby the potential flourishing of new policy paradigms. It also worth noting that challenges of mobility and youth have been widely explored in urban areas, but they have been much less explored with regard to rurality and its consequences for rural development and sustainability. In recent years, discussions on three intersectional topics (rurality, youth, and mobility) have been at the forefront of the debate concerning sustainable rural development as well as of the 2030 agenda adopted by the United Nations [5].

The 2008 economic downturn and the COVID-19 crisis have both exacerbated the growth of youth unemployment in many countries. The figures thereof for 2008-2013 are worse for rural regions: they show higher rates of unemployment and of youth "Not in Education, Employment or Training" [6]. The lack of employment opportunities during the aforementioned years has impelled many rural youths to migrate to urban areas and thereby accelerate depopulation and aging in many regions [7].

The nine articles contained in this Special Issue are connected to one or various topics of the abovementioned intersectional issues. Most of the articles are empirical manuscripts, based in Europe, with the exception of one theoretical piece dealing with the mobility dichotomy and the (im)mobility of rural youth and another that conducts a literature review connected with the involvement of youth in agriculture in Africa.

Youth unemployment represents a significant challenge in Africa. In their review, Geza et al. investigate policies, opportunities, and challenges faced by young people in order to participate in agriculture in Africa. This is achieved by conducting a deep screening of the literature from the perspective of a qualitative data analysis. The authors highlight the weak and pessimistic perceptions of African youth on the ability of agriculture 
to improve their lives and standard of living. This attitude arises from the problems of their participation in agriculture in Africa, such as the production-centric interventions of existing agriculture, low income, and inadequate social protection. The authors recommend that policy makers should pay more attention to the structural problems of youth participation in the economy and consider context-specific integrated agricultural-based interventions to promote significant youth participation in the design of future agricultural and food systems.

Simoes et al. deliver a conceptual, non-empirical paper with the main aim of addressing the concept of farming newcomers. The main contribution of their article is to extend the concept of farming newcomers by proposing the existence of involuntary newcomers and making a basic distinction between them and voluntary newcomers. They also explain the different profiles of involuntary newcomers as determined by spatial (im)mobilities and indicate why the routes of involuntary newcomers into farming are in discrepancy from the sustainable development framework for rural areas. Policy makers need to be aware of a necessity to expand the idea of farming newcomers by proposing the existence of involuntary newcomers. It should be important to introduce them to sustainable forms of agriculture in order to ensure that the sustainable agriculture framework fully meets its intentions and objectives.

Mujcinovic et al. analyse the determinants of Not in Education nor in Employment or Training (NEET) rural youth in three post-transitional countries and compare those situations with that in Ireland (which has similar demographics vis à vis the rural youth population). This is a thoughtfully written piece on how the economic downturn has affected NEET rural youth since 2009 to 2019. Besides the identification of some determinants such as the lack of infrastructure, school dropout rates, high rates of unemployment amongst youth, and the depopulation process, rural areas nonetheless face the migration of youth to urban areas for other reasons. The authors also highlight the absence of specific policies addressing the needs of NEET rural youth in Serbia, Bosnia-Herzegovina, and North Macedonia: in particular, they note that the dominant ideology therein tends to be the traditional approach to development in rural areas, which mostly focuses on the primary sector. In order to build more sustainable rural societies, they recommend policy makers deploy more holistic and targeted approaches by which other sectors (such as tourism or gastronomy) are also taken into account. New lifelong learning opportunities and creating a space for rural youth involvement in the policy process are also suggested.

Baselice et al. emphasise the importance of social agriculture in the agricultural sector. In their project-based paper, they present the importance of an evaluative methodology targeting social agriculture initiatives based on a social innovation initiative. As a case study, the authors chose southern Italy: they evaluate this region via a suitable methodology in order to describe different benefits generated by social agriculture projects. They tested 34 performance indicators and applied them to a project aimed at improving the employability of rural youth NEETs.

Utilising data from eleven European countries, Weiss, Ferrante, and Soler-Porta analyse why rural youth are more willing to move within the country than urban youth but remain less willing to move to another country. The main factors connected to moving are the economy and employment opportunities. The authors remark that whilst the aim of EU policy is to promote youth mobility, there is insufficient effort being made to enhance such geographical mobility. One piece of evidence thereof is that young adults are, in general, unwilling to move to another country to find a job. European policies should take into account youth perspectives and needs concerning mobility in order to be able to explicitly address their unwillingness to be mobile.

In their complex study using a case study of mainland Portugal, Marques da Silva et al. examine mobility as part of the everyday lives of young people growing up in rural border regions. From a policy perspective, they examine how local administrative units deal with contemporary mobility needs and the related consequences. Based on a complex quantitative and qualitative methodology, they emphasise the complex meaning(s) of 
mobility from young people's perspectives. Two aspects are present in their research: young people understand all of the advantages of mobility (as well as the constraints in their daily life relating to their living location), yet at the same time, they tend to learn to stay or return to their region. In terms of policy recommendations, it would be useful to adopt new tendencies considering such peripheral regions where young people accept the durable aspects of their everyday lives. Primarily, these consist of a sense of identity and of belonging to a particular place and the mobilities that come with it.

Simoes et al. examine structural and subjective factors that determine the returning intentions of university students to rural areas. Through a longitudinal study conducted over three years, they observed that those youth less likely to return were those whose mothers have higher education, have high job aspirations, and/or have more attachment to the place where they study. On the contrary, youth in this demographic retain a sense of belonging to their hometowns. Consequently, the authors highlight the need for policymakers to take these emotional bonds into account in order to generate effective policies to combat rural brain drain. They also affirm the need to promote more attractiveness of the agriculture sector as well as other sectors (such as tourism) or a merger of both, i.e., agro-tourism. Thus, more efforts are needed to create and keep emotional bonds to their homelands by strategically targeting them both before they leave and afterwards in order to keep them engaged with the future of their regions whilst living abroad.

Feu and Torrent emphasise that not all rural areas are undergoing a process of depopulation and decline. By drawing on the data of several research projects, they analyse the main reasons why some specific areas are considered to be poles of attraction for youth and young adults. They describe structural and subjective factors that make this trend possible. Amongst them, the most relevant is the existence of a small and innovative school for their future (or current) children. They do this by analysing a case study showing its main features. The authors also emphasise that in order to attract young adults and to re-invigorate rural areas, it is necessary to invest in infrastructure compensating for the regional and historical inequalities against urban areas.

Finally, Alarcón et al. show how the settlement of young refugee families in rural villages may be inclusive and beneficial for sustainability. They present data from a case study where young asylum seekers are provided with mentors (local residents who volunteer) as a way to receive informal social support in their first months after arrival. The authors explain how this mentoring program provides emotional support and cultivates a sense of belonging to the new community by establishing new relationships and by bridging social capital, as Putnam [8] has previously conceptualised. In terms of policy recommendations, these outcomes imply the need to include mentoring programmes in rural development agendas as a way to provide informal support to newcomers and to foster a more humanistic and welcoming environment.

All nine articles of this Special Issue deal with rural sustainability, youth inclusion, and mobility. Specifically, they address issues connected with the agriculture sector and its unequal distribution but also the need for policies to present a more holistic view by including other sectors and specialised professions. Through these analyses, readers can observe how pertinent it is to identify the existing typologies of mobility and (im)mobilities that have been highlighted by these scholars. Moreover, some determinants of inequalities, both structural and subjective, are considered. To that end, the way we should move towards a new paradigm in policy-making (emphasising the need for more knowledge and well-targeted strategies) in order to favour a more equitable rural sustainability within the European Union Green Deal, is also considered.

In recent months, and due to the ongoing COVID-19 pandemic, inland, rural, and border regions have received new attention. Given that they are seen as safer and more natural places and offer new opportunities for remote work, new indicators of regional value, growth, and sustainability and social cohesion are becoming increasingly visible. However, it is still too early to see the extension and intensity of such movements and 
whether they have any impact on the lives of rural youth but also rural sustainability more generally.

Author Contributions: Conceptualisation, S.G. and Ò.P.-F.; writing—original draft preparation, S.G. and Ò.P.-F.; writing - review and editing, S.G. and Oे.P.-F. Both authors have read and agreed to the published version of the manuscript.

Funding: This publication is based upon work from the COST Action CA18213 Rural NEET Youth Network, supported by COST (European Cooperation in Science and Technology); www.cost.eu.

Institutional Review Board Statement: The study was conducted according to the guidelines of the Declaration of Helsinki.

Informed Consent Statement: Not applicable.

Data Availability Statement: This study did not report any data.

Conflicts of Interest: The authors declare no conflict of interest.

\section{References}

1. Rodrigue, J.P. The Geography of Transport Systems. Available online: https://transportgeography.org/ (accessed on 29 September 2020).

2. European Commission. Migration in EU Rural Areas; European Commission: Luxembourg, 2019; Available online: https: //publications.jrc.ec.europa.eu/repository/bitstream/JRC11691901/10/2020 (accessed on 1 October 2020).

3. Freudendal-Pedersen, M. Mobility in Daily Life: Between Freedom and Unfreedom; Ashgate: Farmhan, UK, 2009.

4. Kölbel, A. In Search of a Future: Youth, Aspiration, and Mobility in Nepal; Oxford University Press: Oxford, UK, 2020.

5. International Fund for Agricultural Development. Transforming Rural Lives: Building a Prosperous and Sustainable Future for all. IFAD and the 2030 Agenda for Sustainable Development. 2018. Available online: https://www.ifad.org/en/web/knowledge/-/ publication/transforming-rural-lives-building-a-prosperous-and-sustainable-future-for-all (accessed on 24 August 2021).

6. Alfieri, S.; Ellena, A.M. Rural NEET across Europe, National Reports 2009-2019. COST Action CA 18213: Rural NEET Youth Network: Modeling the Risks Underlying Rural NEETs Social Exclusion. Available online: https:/ /rnyobservatory.eu/web/ (accessed on 15 September 2021).

7. Taibo, C. Iberia Vaciada: Despoblación, Decrecimiento, Colapso; La Catarata: Madrid, Spain, 2020.

8. Putnam, R. Bowling Alone: The Collapse and Revival of American Community; Simon \& Schuster: New York, NY, USA, 2000. 